\title{
Investigating the effects of Pentoxifylline on human breast cancer cells using Raman spectroscopy
}

\author{
Peeyush N. Goel ${ }^{*}$, S. P. Singh ${ }^{\dagger}$, C. Murali Krishna ${ }^{\dagger}$, \\ and R. P. Gude* \\ *Gude Lab, ACTREC, Tata Memorial Center \\ Kharghar, Navi Mumbai 410210 India \\ ${ }^{\dagger}$ Chilakapati Lab, ACTREC, Tata Memorial Center \\ Kharghar, Navi Mumbai 410210 India \\ ${ }^{\sharp}$ mchilakapati@actrec.gov.in
}

Received 21 February 2014

Accepted 24 March 2014

Published 25 April 2014

\begin{abstract}
Breast cancer is one of the leading causes of cancer-related deaths in a global scenario. In the present study, biochemical changes exerted upon Pentoxifylline (PTX) treatment had been appraised in human breast cancer cells using Raman spectroscopy. There are no clinically approved methods to monitor such therapeutic responses available. The spectral profiling is suggestive of changes in DNA, protein and lipid contents showing a linear relationship with drug dosage. Further, multivariate analysis using principal-component based linear-discriminant-analysis (PC-LDA) was employed for classifying the control and the PTX treated groups. These findings support the feasibility of Raman spectroscopy as an alternate/adjunct label-free, objective method for monitoring drug-induced modifications against breast cancer cells.
\end{abstract}

Keywords: Pentoxifylline; MDA-MB-231 breast cancer cells; Raman spectroscopy; spectra; multivariate analysis.

\section{Introduction}

Cancer is the leading cause of worldwide deaths. It is a micro-evolutionary process based on its ability to render genetic alterations, compete and confer unlimited replication potential to the cells. ${ }^{1}$ One of the main reasons for cancer-related deaths is the dissemination of tumor cells to different target sites, a process referred to as metastasis. Breast cancer accounts for the second most leading cause of cancer-related deaths. ${ }^{2}$ The treatment regimen encompasses surgery, radiotherapy followed by chemotherapy. Metastatic breast cancer poses a big challenge for treatment owing to limited therapeutic interventions.

Therapeutic switching or finding newer uses of currently available drugs is one of the most challenging and exciting areas of research in the pharmaceutical industry. ${ }^{3}$ Pentoxifylline (PTX),

This is an Open Access article published by World Scientific Publishing Company. It is distributed under the terms of the Creative Commons Attribution 3.0 (CC-BY) License. Further distribution of this work is permitted, provided the original work is properly cited. 


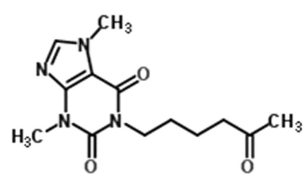

Fig. 1. Structure of Pentoxifylline, a tri-substituted xanthine derivative designated chemically as 1-(5-oxohexyl)-3,7dimethylxanthine.

1-(5-oxohexyl)-3,7-dimethyl-xanthine (structure shown in Fig. 1) belongs to a class of hemorrheologic agents. It is being used in the treatment of peripheral vascular diseases. ${ }^{4}$ Being a phosphodiesterase inhibitor, it elevates the levels of c-AMP thereby affecting various aspects of cellular behavior associated with metastasis. However, various c-AMP elevators such as forskolin, IBMX, dibutryl cAMP are excluded from chemotherapeutic regimens due to their toxicity. ${ }^{5}$ Recently, PTX has been shown to exert anti-metastatic activity in MDA-MB-231 human breast cancer cells. ${ }^{6}$ At sub-toxic doses (1, 2.5 and $5 \mathrm{mM})$, PTX affects cellular proliferation, cellular invasion and migration. It induced a cell cycle block at G1 phase followed by apoptosis. However, alterations in the biochemical design/ structure in breast cancer cells upon PTX treatment needs to be sought out. The biochemical framework comprises of proteins, carbohydrates, lipids and nucleic acid. It is the combinatorial endeavours of these biomolecules that form and regulate the functioning of living organization. Thus, investigation of the changes in the intracellular milieu of breast cancer cells upon PTX treatment will explore its targeted action.

PTX has shown to affect protein catabolism and suppress protein levels promoting hepatoprotective effects. $^{7,8}$ It causes a decrease in oxidized lipid products and alters membrane fluidity.${ }^{9-11}$ Further, it also regulates homologous recombination repair and carbohydrate metabolism. ${ }^{12,13}$ Various modalities such as use of complex cellular techniques, immunohistological analysis for determining drug associated changes are relatively less sensitive and preclude the complete scenario of the associated effects. ${ }^{14}$ Hence, newer techniques that surpass these drawbacks and limitations need to be explored.

Raman spectroscopy, an analytical technique based on vibrational spectroscopy is sensitive to biochemical variations and provides molecular fingerprints. It has been applied to a variety of applications ranging from medicine to forensic sciences. ${ }^{15-18}$ A typical Raman spectrum is the result of inelastic scattering leading to a shift in the frequency of the incident excitation light. The wavelength shift is specific and thus can provide information about chemical and structural state of a biomolecule. The greatest benefit of this technique is its label-free nature and noninvasive perception. ${ }^{19}$ It has the advantage of having minimum interference from water bands which makes it more appropriate for biomedical applications ${ }^{20}$ and provides an easy, chemicalfree and nondestructive method for studying cells in vitro, cell drug interactions as well as for distinguishing neoplastic from normal tissues. ${ }^{21-32}$

Each tumor is composed of several distinct cell populations and thus the potential and efficacy of chemotherapy is largely governed by the presence of most chemosensitive or rather least resistant cell populations. Identification of a resistant/sensitive phenotype in cancer cells from the patients can enhance the efficacy of therapy. Various studies on identification of multi-drug resistant phenotypes in ovarian and leukemic cells had demonstrated the prospective of Raman spectroscopy as an objective and label-free cell sensor. ${ }^{22,33,34}$ Along the similar lines, we have extended our approach to assess the biochemical alterations in breast cancer cells upon PTX treatment at sub-toxic doses.

\section{Materials and Methods}

\subsection{Cell line and culture conditions}

MDA-MB-231, human breast cancer cell line was procured from National Centre for Cell Sciences (NCCS), Pune, India. Cells were maintained in Dulbecco's modified, Eagle medium (DMEM, GIBCO) supplemented with $10 \%$ heat inactivated fetal bovine serum (FBS) (GIBCO) and antibiotics (100 U/ $\mathrm{mL}$ penicillin and $100 \mu \mathrm{g} / \mathrm{mL}$ streptomycin). Cell cultures were maintained at $37^{\circ} \mathrm{C}$ in $5 \% \mathrm{CO}_{2}$ humidified atmosphere.

\subsection{Cell viability assay}

Briefly, 5000 cells/well were seeded into a 96-well plate format. After $24 \mathrm{~h}$, PTX $(1-30 \mathrm{mM})$ was added in complete medium and incubated for another $24 \mathrm{~h}$. $10 \mu \mathrm{L}$ KineticBlue ${ }^{\mathrm{TM}}$ solution was then added into medium and incubated at $37^{\circ} \mathrm{C}$ overnight. Optical density was recorded at $570-600 \mathrm{~nm}$ for the plate and the blank intensity was deducted from the test samples. The results were plotted in a 


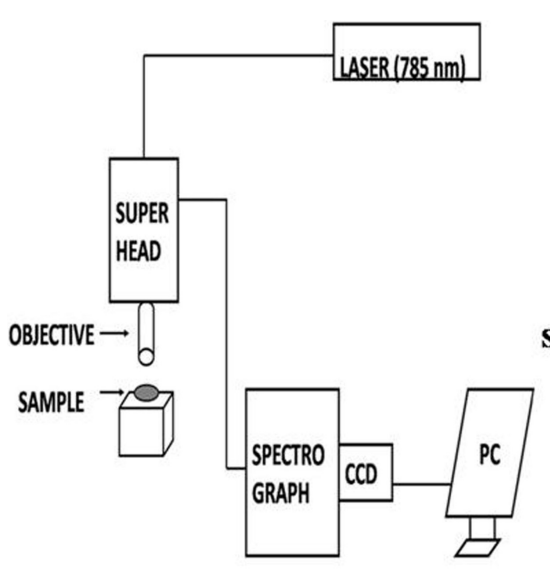

(a)

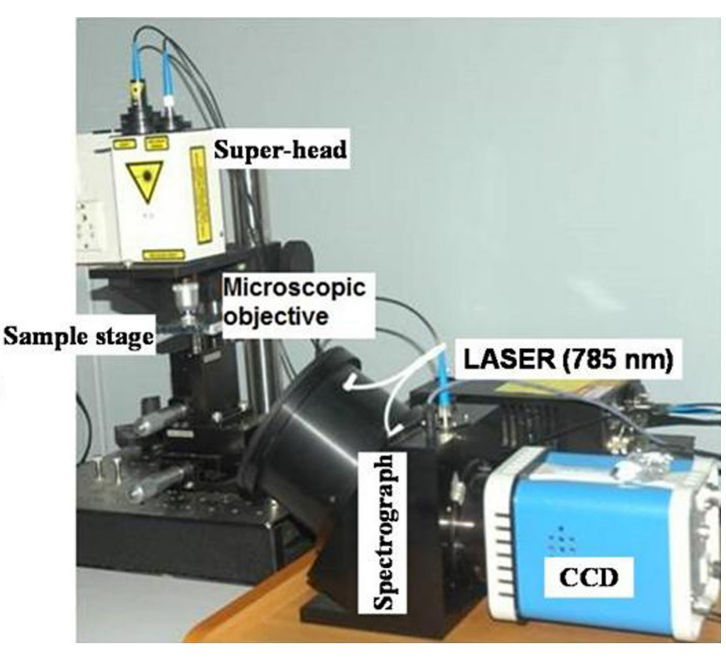

(b)

Fig. 2. Raman microprobe employed for acquiring spectrum from cell pellets. (a) Schematic Representation, (b) Photographic representation.

logarithmic scale where the $x$-axis represents $\%$ viability and the $y$-axis represents concentration of $\operatorname{PTX}(\mathrm{mM})$.

\subsection{Preparation of cells for Raman spectroscopy}

Cells were seeded in $100 \mathrm{~mm}$ plates (BD Biosciences) containing complete medium (DMEM with serum). When the cells reached a confluency of about 70-80\%, plain medium (DMEM without serum) was added for synchronizing cells. Nutritional elimination (by removing serum) is a commonly used method for cell synchronization and causes the cells to accumulate in G1 phase of the cell cycle. Following this, different doses of PTX $(0,1$ 2.5 and $5 \mathrm{mM}$ ) were added to each of the plates and incubated for $24 \mathrm{~h}$. Cells were washed twice with phosphate buffered saline (PBS) and then removed using saline-EDTA. Cells were later harvested by centrifugation at $1500 \mathrm{rpm}$ for $5 \mathrm{~min}$ and cell pellets were collected. Plates were taken in duplicates for control as well as for PTX treated groups and the experiments were repeated thrice.

\subsection{Spectral acquisition}

Raman spectra from cell pellets, placed on a calcium fluoride $\left(\mathrm{CaF}_{2}\right)$ window, were acquired using fiberoptic Raman microprobe system (Horiba-JobinYvon, France). Briefly, the system consisted of a laser of $785 \mathrm{~nm}$ wavelength (PI-ECL-785-300-FC, Process Instruments) as an excitation source, HE 785 spectrograph (Horiba-Jobin-Yvon, France) coupled with CCD (1024x256-BIDD-SYN, Synapse) as dispersion and detection elements, respectively. Optical filtering of unwanted noise, including Rayleigh signals was executed through "SuperHead", the auxiliary component of the system. Optical fibers were employed to connect the excitation and detection systems. Raman microprobe was assembled by coupling a 50X microscopic objective (Nikon, NA 0.8) to the "SuperHead". The spectrograph was equipped with a fixed grating of $950 \mathrm{gr} / \mathrm{mm}$ and spectral resolution as per the manufacturer's specification was $\sim 4 \mathrm{~cm}^{-1}$. Photographic representation of the instrument is shown in Fig. 2. A total of 204 spectra were acquired with the following parameters: laser power- $40 \mathrm{~mW}$, integration time- $10 \mathrm{~s}$ and averaged over six accumulations.

\subsection{Spectral pre-processing and multivariate analysis}

Spectral pre-processing of Raman spectra from the control and PTX treated cells was performed using Labspec 5.0 software (Horiba-Jobin-Yvon) as per the standard protocol described earlier. ${ }^{35,36}$ In the first step, the wavelength dependency of the detector and the polarization dependence of the optical elements were measured using a calibration standard (standard reference material number -2241; 


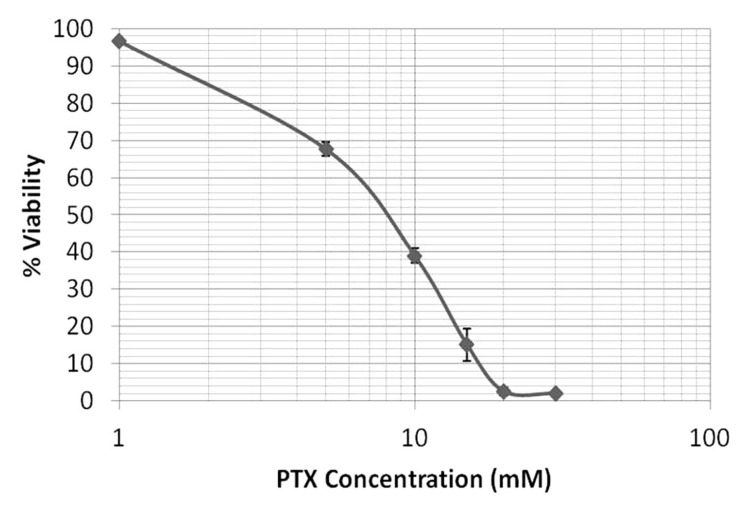

Fig. 3. Cell viability assay. Cells were seeded in 96-well format and different doses of PTX $(1-30 \mathrm{mM})$ were added for $24 \mathrm{~h}$. After, overnight incubation on adding Kinetic blue, absorbance was recorded at 570-600 nm. Results were plotted in log scale where $x$-axis represent $\%$ Viability and $y$-axis corresponds to PTX concentration $(\mathrm{mM})$.

NIST, Gaithersburg, MD, USA). The measured Raman spectra were divided by spectrum associated with the instrument response. Spectral contribution of optical elements i.e., the background signals were obtained by acquiring spectra of $\mathrm{CaF}_{2}$ window without the sample under similar conditions. The response corrected background spectrum was then subtracted. In order to remove the influence of slowmoving fluorescence background, first derivative spectrum was computed using Savitzky-Golay filter mechanism (window size-3). Correction for spectral differences due to relative intensity changes was performed by vector normalization. First derivative and vector normalized spectra were interpolated in $800-1800 \mathrm{~cm}^{-1}$ region ${ }^{16,22,26,28,31-33}$ and used as input for multivariate analysis by principal component-linear discriminant analysis (PC-LDA). PCLDA models were then validated by leave-one-out cross-validation (LOOCV). Algorithms for these analyses were implemented in MATLAB-(Mathworks Inc., USA) based software using in-house codes. ${ }^{37}$

The average spectra were computed from the background subtracted spectra prior to derivatization. This was performed by averaging the $y$-axis variations, keeping the $x$-axis constant for each class and the baseline corrections by fitting a 5thorder polynomial function. These baseline corrected spectra were used for spectral comparisons across all groups. Difference spectra was generated by subtracting the average spectra of cells treated with different sub-toxic concentrations of PTX viz. 1, 2.5 and $5 \mathrm{mM}$, from the control cells.

\section{Results and Discussion}

\subsection{PTX affects cellular viability and proliferation}

The foremost step to elucidate the cytotoxic effects of PTX was to perform a cell viability assay. As shown in Fig. 3, a dose-dependent decrease in cell viability was observed with approximate $100 \%$ cell death at $20 \mathrm{mM}$. Inhibitory concentration ${ }_{50}\left(\mathrm{IC}_{50}\right)$ i.e., the concentration required to kill half the population of cells was observed to be approximately $8 \mathrm{mM}$. A famous axiom in toxicology by Paracelsus states, "The dose makes the poison". As per the doctrine, it is the dose that determines the outcome of a biological process. In our study, we have therefore evaluated the effects of PTX at subtoxic doses i.e., doses exhibiting a maximal of $30 \%$ toxicity or till $\mathrm{IC}_{30}$. Higher doses have been excluded from the same in purview of this rationale. Based on these observations, doses within sub-toxic range were selected i.e., 1, 2.5 and $5 \mathrm{mM}$ for Raman studies. In an independent study, these sub-toxic doses of PTX have shown to minimally affect the normal or nontumorigenic HaCaT cells. The survival fraction of the normal cells at these sub-toxic doses was found to be around $90 \% .{ }^{38}$ In view of reported facts, the sub-toxic doses used in our study were found to be more detrimental against the breast cancer cells compared to normal cells.

PTX affects cellular proliferation which is evident by the viability curve. In our earlier work we had shown that PTX caused a G1 cell cycle block inducing apoptosis in breast cancer cells. ${ }^{6}$ This observation is in accordance to the earlier reports that describe an increase in c-AMP, upon phosphodiesterase inhibition thus inducing a G1 block. c-AMP is $3^{\prime}-5^{\prime}$-cyclic adenosine monophosphate that functions as a secondary messenger. It is known to alter gene expression by its effect on c-AMP response element-binding protein (CREB).

Being a transcription factor, CREB thus regulates gene expression by binding to a DNA sequence (5'-TGACGTCA-3') referred to as the c-AMP response elements (CRE). ${ }^{39}$ In light of this, we propose a similar mode of action for PTX.

\subsection{Analysis of Raman spectral profiles}

Several studies have conclusively demonstrated that wavelength of $660 \mathrm{~nm}$ or above do not induce photodamage. ${ }^{40-43}$ In accordance to these observations 


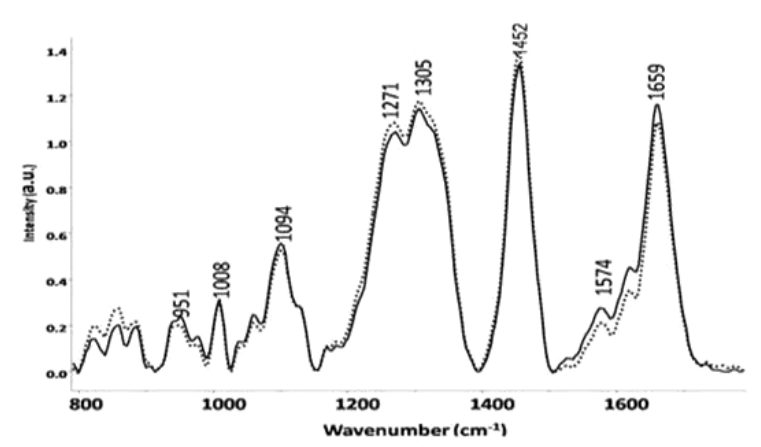

(a)

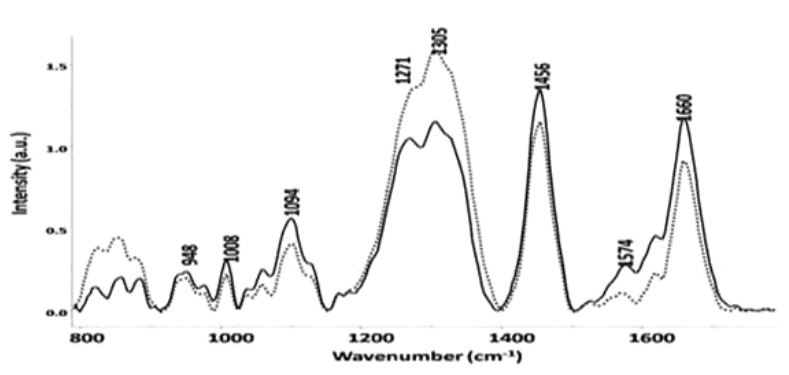

(c)

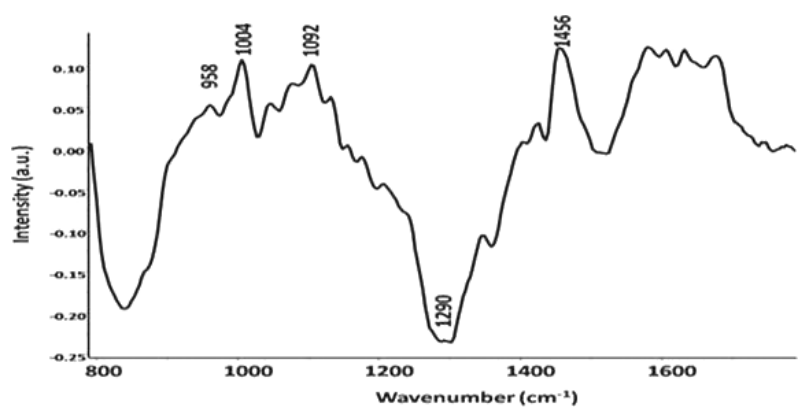

(e)

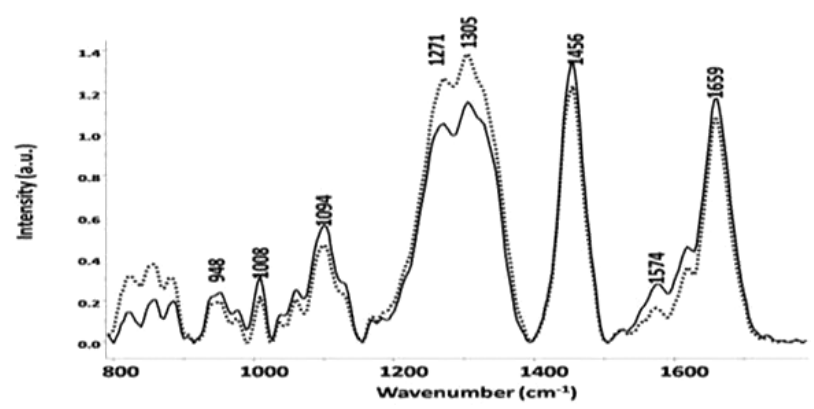

(b)

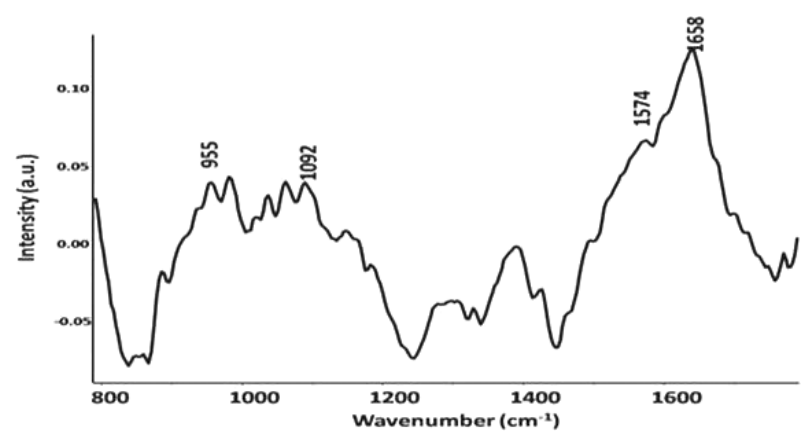

(d)

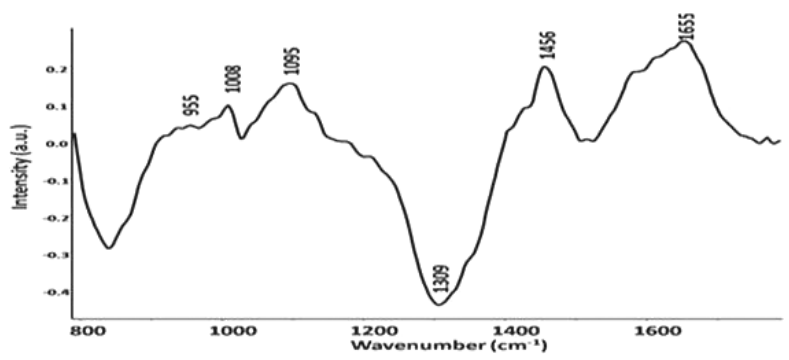

(f)

Fig. 4. Mean spectra of MDA-MB-231 cells: control (solid line), PTX treated (broken line) (a)-1 mM, (b)-2.5 mM, (c)-5 mM. Comparison of difference spectra across control and treatment groups (d): Control - $1 \mathrm{mM} \mathrm{PTX} \mathrm{treatment,} \mathrm{(e):} \mathrm{Control-} 2.5 \mathrm{mM}$ PTX treatment and (f): Control $-5 \mathrm{mM}$ PTX treatment.

in the present study, breast cancer cells treated with PTX that were exposed to $785 \mathrm{~nm}$ excitation do not show any photodamage. Therefore, the observed differences in the spectra could be attributed to differential drug treatment regimens.

The mean baseline corrected Raman spectra in the range of $800-1800 \mathrm{~cm}^{-1}$ for the control (solid line) and PTX treated (broken line) MDA-MB-231 cells for $24 \mathrm{~h}$ are shown in Figs. 4(a)-4(c). Differences in Raman bands associated with DNA backbone, DNA ring bases, lipids and protein vibrations were observed. The band at $1094 \mathrm{~cm}^{-1}$ is considered as an internal standard for DNA content and has been assigned to the symmetric stretching vibration mode of $\mathrm{PO}^{2-}$ backbone in DNA. As can be seen from Figs. 4(a) $-4(\mathrm{c})$, intensity of the peak at $1094 \mathrm{~cm}^{-1}$ is less in PTX-treated groups in comparison to the controls, suggesting changes in the DNA content due to drug intervention. This observation is also supported by a similar variation observed in the guanine band at $1576 \mathrm{~cm}^{-1}$. Cells treated with $5 \mathrm{mM}$ PTX showed low DNA content as compared to control and the other treatment groups. A linear increase with drug dosage was 
observed for the bands around $1280 \mathrm{~cm}^{-1}(=\mathrm{CH}$ bending of lipids) and $1305 \mathrm{~cm}^{-1}\left(\mathrm{CH}_{3} / \mathrm{CH}_{2}\right.$ bending of phospholipids) suggesting changes in lipid profile upon PTX exposure. ${ }^{44-47}$ This is in concordance with already mentioned reports on PTX affecting membrane fluidity by altering lipids. ${ }^{9-11}$ Minor changes in free amino acids indicated by the bands around $950 \mathrm{~cm}^{-1}$ (proline), phenylalanine $\left(1008 \mathrm{~cm}^{-1}\right), 1620 \mathrm{~cm}^{-1}$ (tryptophan), suggesting changes in overall protein content after drug treatment were also observed. This is further supported by the decrease in the intensity of amide I band around $1660 \mathrm{~cm}^{-1}$. Alterations in these bands serve as a probe for the conformational variability, which could arise due to drug treatment. The intensity of the band at $1660 \mathrm{~cm}^{-1}$ decreases linearly with drug dosage in the treatment groups with respect to control, suggesting a decrease in the protein content upon drug treatment.

In the next step, to highlight the spectral differences between the control and treatment groups distinctly, difference spectra were computed. The subtraction of mean spectra is one of the conventional ways of identifying spectral differences over a selected spectral range. It can provide the information regarding moieties being altered. The mean spectra of cells treated with $1,2.5$ and $5 \mathrm{mM}$ PTX were subtracted from that of the control group. The positive bands characterize the control group while the negative bands represent PTX-treated groups. A reduction in the protein and DNA content marked by positive amide I $\left(1660 \mathrm{~cm}^{-1}\right)$ and DNA $\left(1094 \mathrm{~cm}^{-1}\right)$ bands was observed, Fig. 4(d). These differences were more pronounced in cells treated with higher doses of PTX i.e., 2.5 and $5 \mathrm{mM}$. Changes in lipid profile due to drug treatment, evident by the negative bands around 1280 and $1305 \mathrm{~cm}^{-1}$, were also observed. As shown in Figs. 4(e) and 4(f), the intensity of positive DNA band $\left(1094,1574 \mathrm{~cm}^{-1}\right)$ was highest for the cells treated with $5 \mathrm{mM}$ drug, indicating that the cells treated with $5 \mathrm{mM}$ PTX have the lowest DNA content. This observation was consistent with the other two doses as well. These changes can be attributed to the fact that increase in c-AMP, upon PTX treatment, leads to differential regulation of CRE sequences of DNA. This sequence consists of guanine nucleotides and thus can be designated as a point for this distinctive execution. PTX has been earlier shown to inhibit DNA content of neuroblastoma cells. ${ }^{11}$ Further it decreases cells in S phase (duplication phase) which is also indicative of decrease in DNA content. Positive bands at phenylalanine, $\mathrm{CH}_{2}\left(1450 \mathrm{~cm}^{-1}\right)$, and amide I suggest that cells treated with PTX exhibited decrease in overall protein content in comparison to the control group. Overall, major changes in DNA, protein and lipids were observed upon drug treatment. These changes do appear to have a linear relationship with drug concentration i.e., cells treated with highest dose of $5 \mathrm{mM}$ exhibits maximal changes followed by 1 and $2.5 \mathrm{mM}$ dosage, respectively.

\subsection{Multivariate analysis}

The next step of classification between control and treated cells was explored using the PC-LDA method. PCA is a routinely used method for data compression and visualization. It describes data variance by identifying a new set of orthogonal features known as principal components (PCs) or factors. For visual discrimination, we project each of the spectra in the newly formed co-ordinate space of selected PCs. While PCA aims to identify features that represent variance among complete data, LDA provides data classification based on an optimized criteria leading to better class separation. In LDA, the classification criterion is identified using the scatter measure of within class and between class variance. LDA can be used in companion with PCA to increase the efficiency of the classification. For this, PCA scores obtained using a set of significant $\mathrm{PCs}$ with maximum variance amongst data, are used as input data for LDA-based classification. It has an advantage of eliminating or minimizing noise from the data and concentrates on variables important for classification. In our analysis, significant PCs $(p<0.05)$ were selected as input for LDA. In order to avoid over-fitting of the data, as a thumb rule, total number of factors selected for analysis were less than half the number of the spectra in the smallest group. ${ }^{48-50}$ First derivative and vector normalized spectra were fed in to MATLAB-based algorithm and PC-LDA using 15 factors with $\sim 73 \%$ classification efficiency was performed. Profiles of PCs also known as factor loadings can provide vital clues on biochemical variations among different classes. Loading plots of factor 1 and 2 that lead to delineation among control and treated groups are presented in Fig. 5. Corroborating spectral variability suggested by difference spectra loading plots also suggest differences in protein and lipid content of control and 


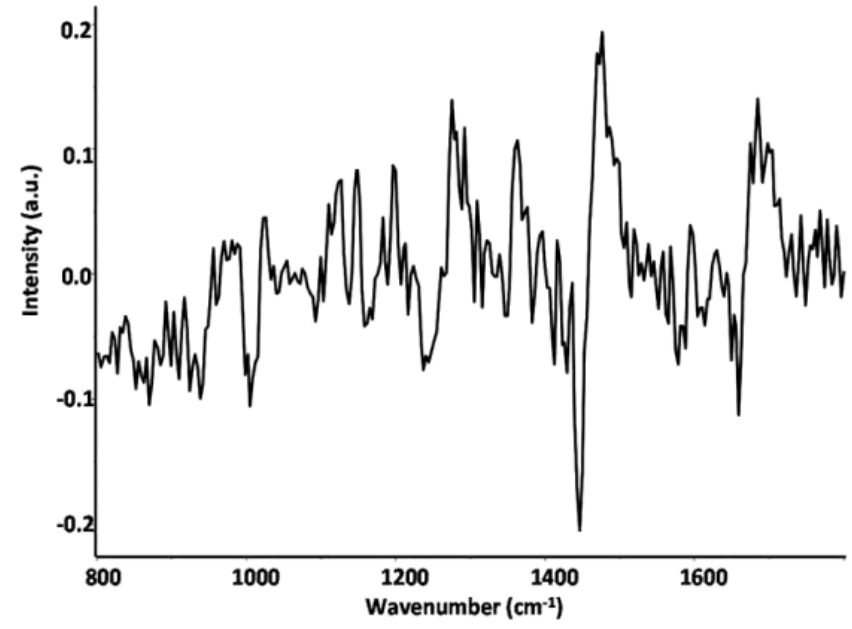

(a)

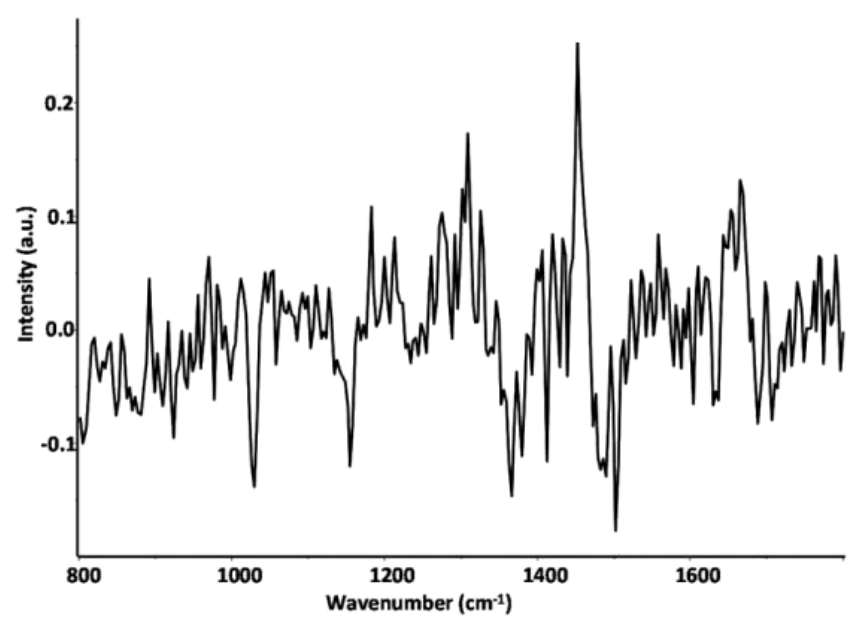

(b)

Fig. 5. Loading plots of factors used for classification (a) Factor 1 (b) Factor 2.

treated group. The first PC (PC1) has two major bands that correspond to $\mathrm{CH}_{3} / \mathrm{CH}_{2}$ bending modes of phospholipids and $\mathrm{CH}_{2}$ stretching modes, respectively. In the second component (PC2) the main peak features correspond to $=\mathrm{CH}$ bending of lipids and amide I, in addition to smaller bands similar to PC1.

The scatter plot generated using score of factor 1 and factor 2 is shown in Fig. 6. It can be seen that the spectra of cells treated with $1 \mathrm{mM}$ drug ( $)$ showed an overlap with control cells $(\triangle)$ while separate clusters belonging to the spectra from other two groups i.e., $2.5(\boldsymbol{\square})$ and $5 \mathrm{mM}(\bullet)$ were obtained. This observation can be best explained as per the fact that, as $1 \mathrm{mM}$ corresponds to the lowest sub-toxic dose, it might have a minimal effect on the biochemical environment of cells in comparison to cells treated with other two higher sub-toxic doses. The same results are presented in Table 1 . As can be seen, 39/53 spectra of control cells were correctly classified. A total of 14 spectra were misclassified, of these 10 were with cells treated with $1 \mathrm{mM}$ drug

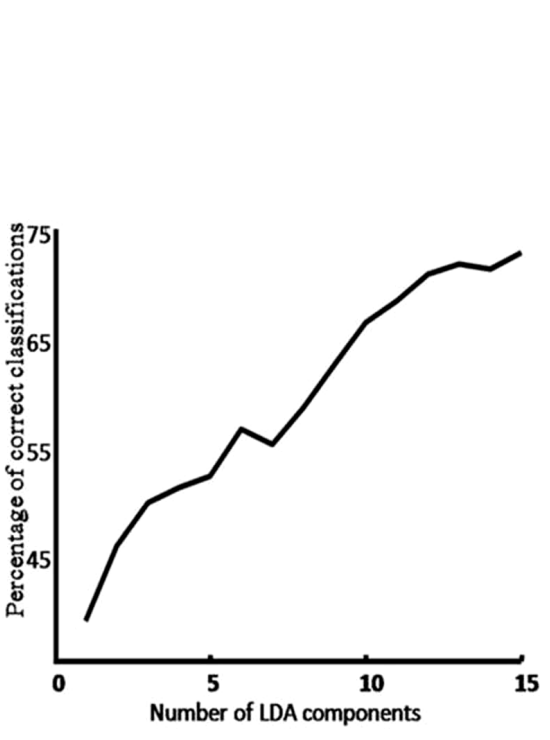

(a)

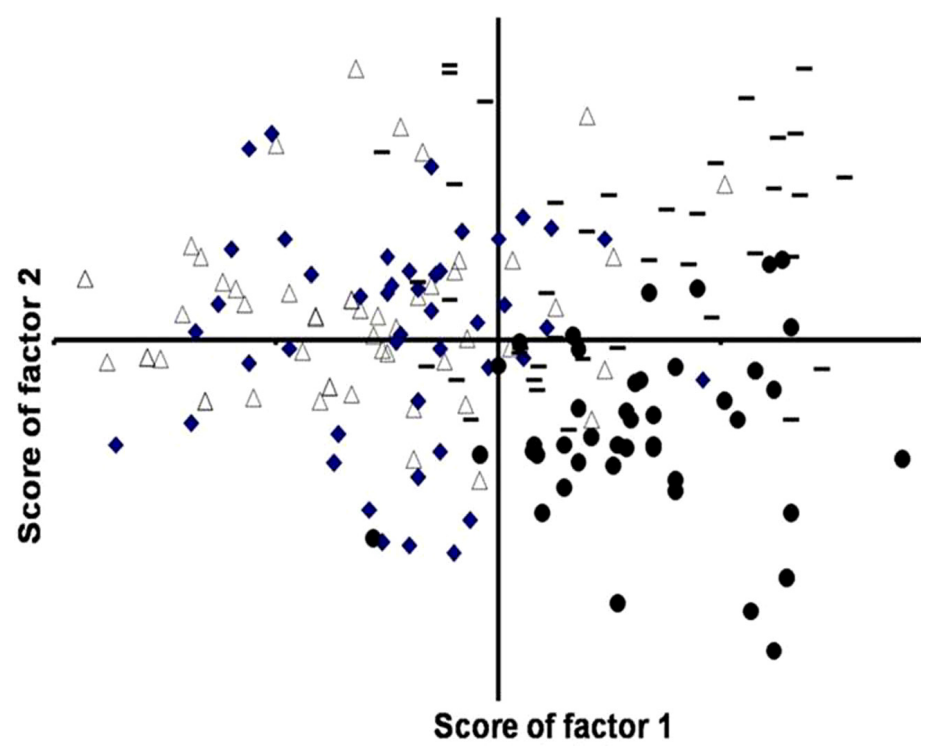

(b)

Fig. 6. PC-LDA of control cells $(\triangle)$ and the cells treated with $1(\bullet), 2.5(\boldsymbol{\square})$, and $5 \mathrm{mM}$ drug doses $(\bullet)$. (a) Scree plot (b) Scatter plot. 
Table 1. Summary of classifcation after PC-LDA and LOOCV between control and PTX-treated MDA-MB-231 cells (diagonal elements are true positive predictions and ex-diagonal elements are false positive predictions).

\begin{tabular}{lllll}
\hline & Untreated & $1 \mathrm{mM}$ & $2.5 \mathrm{mM}$ & $5 \mathrm{mM}$ \\
\hline Untreated & $39 / 53$ & 10 & 1 & 3 \\
$1 \mathrm{mM}$ & 7 & $37 / 53$ & 6 & 3 \\
$2.5 \mathrm{mM}$ & 2 & 5 & $33 / 47$ & 7 \\
$5 \mathrm{mM}$ & 3 & 1 & 8 & $39 / 51$ \\
Leave-one-out-cross validation & & & \\
Untreated & $29 / 53$ & 17 & 3 & 4 \\
$1 \mathrm{mM}$ & 10 & $32 / 53$ & 7 & 4 \\
$2.5 \mathrm{mM}$ & 7 & 8 & $23 / 47$ & 9 \\
$5 \mathrm{mM}$ & 5 & 1 & 14 & $31 / 51$ \\
\hline
\end{tabular}

dose and remaining 4 with other two doses i.e., 2.5 and $5 \mathrm{mM}$. A similar trend was observed for cells treated with $1 \mathrm{mM}$ drug dose, here $37 / 53$ spectra were correctly classified (70\%) and maximum misclassifications were observed with control cells. This can be explained on the basis of previously described fact that cells treated with $1 \mathrm{mM}$ dose might not have acquired enough changes in their biochemical milieu with respect to control or untreated cells. Further, a dose of $1 \mathrm{mM}$ exerts mere $10 \%$ cytotoxicity and therefore misclassification with control cell population is expected. In case of cells treated with $2.5 \mathrm{mM}$ or the median drug dose, $33 / 47$ spectra were correctly classified $(70 \%)$. Here of the 14 misclassifications, 7 were with cells treated with $5 \mathrm{mM}$ drug dose. Only two spectra were misclassified with control group. Similarly, in case of cells treated with $5 \mathrm{mM}$ drug dose, 39/51 spectra were correctly classified $(76 \%)$. Of the 12 misclassifications, 8 were with cells treated with $2.5 \mathrm{mM}$ drug dose and only 1 spectrum was misclassified with the control cells, suggesting that cells had undergone biochemical changes reflected by the decreased misclassification with the control group. In addition, we had employed LOOCV, a commonly used method for the validation of results of supervised analysis, in the absence of an independent test dataset. As can be seen from Table 1, 29 of the 53 spectra from control groups were correctly classified; of the 24 misclassification, 17 blend with cells treated with minimal drug dose i.e., $1 \mathrm{mM}$. Similarly, of the total 53 spectra acquired from cells treated with $1 \mathrm{mM}$ drug, 32 were correctly classified and among 21 misclassifications, 10 were with the control group which was consistent with our earlier observations. Further, of the total 47 spectra of cells treated with $2.5 \mathrm{mM}, 23$ were correctly classified. A closer view of Table 1 reveals that the misclassifications were distributed across all the groups with minimal numbers contributed by the untreated group. About 31 out of 51 spectra from cells treated with $5 \mathrm{mM}$ drug dose were correctly assorted. Most importantly, only 5 and 1 spectra were misclassified with control and cells treated with $1 \mathrm{mM}$ dose, respectively. Overall findings indicate that control and treated cells can be categorized but with a varying efficiency. The differential sensitivity of cells in a pellet toward PTX treatment could be a plausible explanation for such misclassifications. It should be noteworthy that most of the misclassifications are among groups harboring overlapping features. Further, the doses used in our studies i.e., 1, 2.5 and $5 \mathrm{mM}$ are relatively sub-toxic and far below the cytotoxic dose of the drug. The maximal toxicity undertaken in the present study at $5 \mathrm{mM}$ dose is around $30 \%$. Thus, overlaps and misclassifications are expected within the different doses under investigation. At higher toxic doses, such misclassifications may be minimal but such high doses shall be deleterious for cells. These high doses are generally avoided from therapeutic point of view and thus had been excluded in the present study as well.

Additionally, it is important to note that Raman spectra in the present study were acquired using cell pellets rather than single cells. As per the manufacturer specifications, the laser spot size of the setup is $\sim 5-10 \mu \mathrm{m}$ and the probing volume is $\sim 500$ cubic microns suggesting that in a pellet, the probing beam can encounter a stack of heterogeneous population of cells (drug sensitive or resistant) raising a possibility that the probed area could be at many different cellular components as well as many cells.

\section{Conclusions}

Earlier studies on cell pellets had demonstrated the potential of Raman spectroscopy in classifying single cell type among a mixed cancer cell population, HPV detection, discrimination of wild and multidrug resistant cell types. ${ }^{22,33,34,51,52}$ In the present study, we had explored the usage of cell pellets to identify the cellular changes impinged upon PTX treatment. Mean and difference spectra suggest 
major changes in DNA, lipid and protein profile of cells due to drug treatment, which is consistent with existing literature. These changes appear to have a linear relationship with drug dosage. Variations in DNA content can be primarily due to increase in c-AMP level that regulates the action of CREB protein, a transcription factor that affects the CRE of DNA. Multivariate analysis PC-LDA demonstrated the feasibility of categorizing control and treated groups. Overlaps among spectra of cells treated with different drug doses can be ascribed to differential activity of the drug on cells, selection of relatively sub-toxic doses and presence of heterogeneous (sensitive/resistant) cell populations. The findings of the study supports the applicability of Raman spectroscopic method as a valuable real time, label-free cell sensor in assessing PTX induced differential changes in breast cancer cells.

\section{Conflict of Interest}

None Declared

\section{Acknowledgments}

We acknowledge grant support from ACTREC, Tata Memorial Centre. Mr. Peeyush N. Goel is supported by CSIR-Senior Research fellowship and Mr. S. P. Singh is supported by ACTREC Senior Research fellowship. The Raman spectrometer employed in the study was procured from DBT project BT/PRI11282/MED/32/83/2008, entitled "Development of in vivo laser Raman spectroscopy methods for diagnosis of oral precancerous and cancerous conditions, Department of Biotechnology, Government of India".

\section{References}

1. G. Tarafa, D. Tuck, D. Ladner, M. Topazian, R. Brand, C. Deters, V. Moreno, G. Capella, H. Lynch, P. Lizardi, J. Costa, "Mutational load distribution analysis yields metrics reflecting genetic instability during pancreatic carcinogenesis," Proc. Natl. Acad. Sci. USA 105, 4306-4311 (2008).

2. J. Ferlay, H. R. Shin, F. Bray, D. Forman, C. Mathers, D. M. Parkin, "Estimates of worldwide burden of cancer in 2008: GLOBOCAN 2008," Int. J. Cancer 127, 2893-2917 (2010).

3. A. Mullard, "Could pharma open its drug freezers?," Nat. Rev. Drug. Discov. 10(6), 399-400 (2011).
4. M. Zhang, Y. J. Xu, S. A. Mengi, A. S. Arneja, N. S. Dhalla, "Therapeutic potentials of pentoxifylline for treatment of cardiovascular diseases," Exp. Clin. Cardiol. 9(2), 103-111 (2004).

5. L. Hirsh, A. Dantes, B. S. Suh, Y. Yoshida, K. Hosokawa, K. Tajima, F. Kotsuji, O. Merimsky, A. Amsterdam, "Phosphodiesterase inhibitors as anti-cancer drugs," Biochem. Pharmacol. 68(6), 981-988 (2004).

6. P. N. Goel, R. P. Gude, "Unravelling the antimetastatic potential of pentoxifylline, a methylxanthine derivative in human MDA-MB-231 breast cancer cells," Mol. Cell. Biochem. 358(1-2), 141-151 (2011).

7. G. Biolo, B. Ciocchi, A. Bosutti, R. Situlin, G. Toigo, G. Guarnieri, "Pentoxifylline acutely reduces protein catabolism in chronically uremic patients," $A m$. J. Kidney Dis. 40(6), 1162-1172 (2002).

8. M. K. Chae, S. G. Park, S.-O. Song, E. S. Kang, B. S. Cha, H. C. Lee, B.-W. Lee, "Pentoxifylline attenuates Methionine- and Choline-deficient-dietinduced steatohepatitis by suppressing TNF- $\alpha$ expression and endoplasmic reticulum stress," Exp. Diabetes Res. 2012, 1-8 (2012).

9. C. O. Zein, R. Lopez, X. Fu, J. P. Kirwan, L. M. Yerian, A. J. McCullough, S. L. Hazen, A. E. Feldstein, "Pentoxifylline decreases oxidized lipid products in nonalcoholic steatohepatitis: New evidence on the potential therapeutic mechanism," Hepatology 56(4), 1291-1299 (2012).

10. Y. Sato, T. Miura, Y. Suzuki, "Interaction of pentoxifylline with human erythrocytes. III. Comparison of fluidity change of erythrocyte membrane caused by S-adenosyl-L-methionine with that by pentoxifylline," Chem. Pharm. Bull. (Tokyo) 39(2), 468-473 (1991).

11. A. Amirkhosravi, G. Warnes, J. Biggerstaff, Z. Malik, K. May, J. L. Francis, "The effect of pentoxifylline on spontaneous and experimental metastasis of the mouse Neuro2a neuroblastoma," Clin. Exp. Metastasis 15(4), 453-461 (1997).

12. L. Bohm, "Inhibition of homologous recombination repair with Pentoxifylline targets G2 cells generated by radiotherapy and induces major enhancements of the toxicity of cisplatin and melphalan given after irradiation," Radiat. Oncol. 1(1), 12 (2006).

13. S. S. B. R. Ambrus Jl, "EFfect of pentoxifylline on carbohydrate metabolism in type ii diabetics," Arch. Intern. Med. 150(4), 921-921 (1990).

14. D. Lin, J. Lin, Y. Wu, S. Feng, Y. Li, Y. Yu, G. Xi, H. Zeng, R. Chen, "Investigation on the interactions of lymphoma cells with paclitaxel by Raman spectroscopy," Spectroscopy 25(1), 23-32 (2011).

15. E. V. Efremov, F. Ariese, C. Gooijer, "Achievements in resonance Raman spectroscopy review of a 
technique with a distinct analytical chemistry potential," Anal. Chim. Acta.606(2), 119-134(2008).

16. A. Nijssen, S. Koljenovic, T. C. Bakker Schut, P. J. Caspers, G. J. Puppels, "Towards oncological application of Raman spectroscopy," J. Biophotonics 2(1-2), 29-36 (2009).

17. E. B. Hanlon, R. Manoharan, T. W. Koo, K. E. Shafer, J. T. Motz, M. Fitzmaurice, J. R. Kramer, I. Itzkan, R. R. Dasari, M. S. Feld, "Prospects for in vivo Raman spectroscopy," Phys. Med. Biol. 45(2), R1-59 (2000).

18. A. Mahadevan-Jansen, R. R. Richards-Kortum, "Raman spectroscopy for the detection of cancers and precancers," J. Biomed. Opt. 1(1), 31-70 (1996).

19. J. R. Baena, B. Lendl, "Raman spectroscopy in chemical bioanalysis," Curr. Opin. Chem. Biol. 8 (5), 534-539 (2004).

20. D. Naumann, "FT-Infrared and FT-Raman spectroscopy in biomedical research," App. Spectrosc. Rev. 236(2-3), 239-298 (2001)

21. K. W. Short, S. Carpenter, J. P. Freyer, J. R. Mourant, "Raman spectroscopy detects biochemical changes due to proliferation in mammalian cell cultures," Biophys. J. 88(6), 4274-4288 (2005).

22. C. M. Krishna, G. Kegelaer, I. Adt, S. Rubin, V. B. Kartha, M. Manfait, G. D. Sockalingum, "Combined Fourier transform infrared and Raman spectroscopic approach for identification of multidrug resistance phenotype in cancer cell lines," Biopolymers 82(5), 462-470 (2006).

23. R. J. Swain, G. Jell, M. M. Stevens, "Non-invasive analysis of cell cycle dynamics in single living cells with Raman micro-spectroscopy," J. Cell. Biochem. 104(4), 1427-1438 (2008).

24. M. V. Chowdary, K. K. Kumar, J. Kurien, S. Mathew and C. M. Krishna, "Discrimination of normal, benign, and malignant breast tissues by Raman spectroscopy," Biopolymers 83(5), 556-569 (2006).

25. R. Malini, K. Venkatakrishna, J. Kurien, K. M. Pai, L. Rao, V. B. Kartha, C. M. Krishna, "Discrimination of normal, inflammatory, premalignant, and malignant oral tissue: A Raman spectroscopy study," Biopolymers 81(3), 179-193 (2006).

26. J. Guo, W. Cai, B. Du, M. Qian, Z. Sun, "Raman spectroscopic investigation on the interaction of malignant hepatocytes with doxorubicin," Biophys. Chem. 140(1-3), 57-61 (2009).

27. W. Xie, Y. Ye, A. Shen, L. Zhou, Z. Lou, X. Wang, J. Hu, "Evaluation of DNA-targeted anti-cancer drugs by Raman spectroscopy," Vib. Spectrosc. 47(2), 119-123 (2008).

28. S. Akyuz, A. E. Ozel, K. Balci, T. Akyuz, A. Coker, E. D. Arisan, N. Palavan-Unsal, A. Ozalpan, "Raman micro-spectroscopic analysis of cultured
HCT116 colon cancer cells in the presence of roscovitine," Spectrochim. Acta A Mol. Biomol. Spectrosc. 78(5), 1540-1547 (2011).

29. K. Brautigam, T. Bocklitz, M. Schmitt, P. Rosch, J. Popp, "Raman spectroscopic imaging for the realtime detection of chemical changes associated with docetaxel exposure," Chemphyschem 14(3), 550553 (2013).

30. R. N. Aravalli, J. Choi, S. Mori, D. Mehra, J. Dong, J. C. Bischof, E. N. Cressman, "Spectroscopic and calorimetric evaluation of chemically induced protein denaturation in $\mathrm{HuH}-7$ liver cancer cells and impact on cell survival," Technol. Cancer Res. Treat. 11(5), 467-473 (2012).

31. K. Hartmann, M. Becker-Putsche, T. Bocklitz, K. Pachmann, A. Niendorf, P. Rosch, J. Popp, "A study of Docetaxel-induced effects in MCF-7 cells by means of Raman microspectroscopy," Anal. Bioanal. Chem. 403(3), 745-753 (2012).

32. K. le Roux, L. C. Prinsloo, A. A. Hussein, N. Lall, "A micro-Raman spectroscopic investigation of leukemic U-937 cells treated with Crotalaria agatiflora Schweinf and the isolated compound madurensine," Spectrochim. Acta A Mol. Biomol. Spectrosc. 95, 547-554 (2012).

33. C. Murali Krishna, G. Kegelaer, I. Adt, S. Rubin, V. B. Kartha, M. Manfait, G. D. Sockalingum, "Characterisation of uterine sarcoma cell lines exhibiting MDR phenotype by vibrational spectroscopy," Biochim. Biophys. Acta 1726(2), 160-167 (2005).

34. C. M. Krishna, G. D. Sockalingum, G. Kegelaer, S. Rubin, V. B. Kartha, M. Manfait, "Micro-Raman spectroscopy of mixed cancer cell populations," Vib. Spectrosc. 38(1), 95-100 (2005).

35. A. Nijssen, K. Maquelin, L. F. Santos, P. J. Caspers, T. C. Bakker Schut, J. C. den Hollander, M. H. Neumann, G. J. Puppels, "Discriminating basal cell carcinoma from perilesional skin using high wavenumber Raman spectroscopy," J. Biomed. Opt. 12 (3), 034004 (2007).

36. S. P. Singh, A. Sahu, A. Deshmukh, P. Chaturvedi, C. M. Krishna, "In vivo Raman spectroscopy of oral buccal mucosa: A study on malignancy associated changes (MAC)/cancer field effects (CFE)," Analyst 138(14), 4175-4182 (2013).

37. A. D. Ghanate, S. Kothiwale, S. P. Singh, D. Bertrand, C. M. Krishna, "Comparative evaluation of spectroscopic models using different multivariate statistical tools in a multicancer scenario," $J$. Biomed. Opt. 16(2), 025003 (2011).

38. A. Bravo-Cuellar, P. C. Ortiz-Lazareno, J. M. LermaDiaz, J. R. Dominguez-Rodriguez, L. F. Jave-Suarez, A. Aguilar-Lemarroy, S. del Toro-Arreola, R. de CelisCarrillo, J. E. Sahagun-Flores, J. E. de Alba-Garcia, 
G. Hernandez-Flores, "Sensitization of cervix cancer cells to Adriamycin by Pentoxifylline induces an increase in apoptosis and decrease senescence," Mol. Cancer 9, 114-127 (2010).

39. A. J. Shaywitz, M. E. Greenberg, "CREB: A stimulus-induced transcription factor activated by a diverse array of extracellular signals," Annu. Rev. Biochem. 68 821-861 (1999).

40. G. J. Puppels, F. F. M. de Mul, C. Otto, J. Greve, M. Robert-Nicoud, D. J. Arndt-Jovin, T. M. Jovin, "Studying single living cells and chromosomes by confocal Raman microspectroscopy," Nature $\mathbf{3 4 7}$ (6290), 301-303 (1990).

41. G. J. Puppels, H. S. Garritsen, G. M. Segers-Nolten, F. F. de Mul, J. Greve, "Raman microspectroscopic approach to the study of human granulocytes," Biophys. J. 60(5), 1046-1056 (1991).

42. G. J. Puppels, J. H. F. Olminkhof, G. M. J. SegersNolten, C. Otto, F. F. M. de Mul, J. Greve, "Laser irradiation and Raman spectroscopy of single living cells and chromosomes: Sample degradation occurs with $514.5 \mathrm{~nm}$ but not with $660 \mathrm{~nm}$ laser light," Exp. Cell Res. 195(2), 361-367 (1991).

43. F. Bonnier, S. M. Ali, P. Knief, H. Lambkin, K. Flynn, V. McDonagh, C. Healy, T. C. Lee, F. M. Lyng, H. J. Byrne, "Analysis of human skin tissue by Raman microspectroscopy: Dealing with the background," Vib. Spectrosc. 61(0), 124-132 (2012).

44. S. R. Hawi, W. B. Campbell, A. Kajdacsy-Balla, R. Murphy, F. Adar, K. Nithipatikom, "Characterization of normal and malignant human hepatocytes by Raman microspectroscopy," Cancer Lett. 110(1-2), 35-40 (1996).

45. W. T. Cheng, M. T. Liu, H. N. Liu, S. Y. Lin, "Micro-Raman spectroscopy used to identify and grade human skin pilomatrixoma," Microsc. Res. Tech. 68(2), 75-79 (2005).

46. Z. Movasaghi, S. Rehman, I. U. Rehman, "Raman spectroscopy of biological tissues," App. Spectrosc. Rev. 42(5), 493-541 (2007).

47. I. Notingher, C. Green, C. Dyer, E. Perkins, N. Hopkins, C. Lindsay, L. L. Hench, "Discrimination between ricin and sulphur mustard toxicity in vitro using Raman spectroscopy," J. R. Soc. Interface 1(1), 79-90 (2004).

48. T. C. Bakker Schut, R. Wolthuis, P. J. Caspers, G. J. Puppels, "Real-time tissue characterization on the basis of in vivo Raman spectra," J. Raman Spectrosc. 33(7), 580-585 (2002).

49. P. Crow, B. Barrass, C. Kendall, M. Hart-Prieto, M. Wright, R. Persad, N. Stone, "The use of Raman spectroscopy to differentiate between different prostatic adenocarcinoma cell lines," Br. J. Cancer 92(12), 2166-2170 (2005).

50. T. J. Harvey, E. Gazi, A. Henderson, R. D. Snook, N. W. Clarke, M. Brown, P. Gardner, "Factors influencing the discrimination and classification of prostate cancer cell lines by FTIR microspectroscopy," Analyst 134(6), 1083-1091 (2009).

51. E. Vargis, Y. W. Tang, D. Khabele, A. MahadevanJansen, "Near-infrared Raman microspectroscopy detects high-risk human papillomaviruses," Transl. Oncol. 5(3), 172-179 (2012).

52. K. M. Ostrowska, A. Malkin, A. Meade, J. O'Leary, C. Martin, C. Spillane, H. J. Byrne, F. M. Lyng, "Investigation of the influence of high-risk human papillomavirus on the biochemical composition of cervical cancer cells using vibrational spectroscopy," Analyst 135(12), 3087-3093 (2010). 